\title{
Complying with the United Nations' Sustainable Development Goals: A case of the Malaysian ageing population
}

\author{
Khairiah Salwa Mokhtar ${ }^{1}$, Nurulhasanah Abdul Rahman ${ }^{1 *}$, Mahmod Sabri Haron $^{2}$ \\ ${ }^{1}$ Political Science Department, School of Distance Education, Universiti Sains Malaysia, 11800 Penang, Malaysia \\ ${ }^{2}$ School of Management, Universiti Sains Malaysia, 11800 Penang, Malaysia
}

\begin{abstract}
Objective - The rapid growth in the ageing population necessitates a more intensified effort to include patients of all ages in global sustainable development. While many countries struggle to manage their ageing populations, efforts to ensure adequate health are alarmingly unconvincing. In fact, the spread of infectious diseases, especially Tuberculosis (TB), within the ageing population remains a threat to meet the United Nations' Sustainable Development Goals. Studies related to the ageing population in Malaysia are rather limited and their perspectives on infectious disease patients are often neglected.

Methodology/Technique - Therefore, this study aims to investigate the perspective of ageing tuberculosis patients on preventive measures and to what extent their behaviour helps Malaysia to comply with the United Nations' Sustainable Development Goals. Of 1,600 patients to whom questionnaires were sent, 1,368 completed questionnaires that were used for further analysis. This study was conducted in 2015 within selected states of Malaysia with high occurrence rates of TB cases.

Finding - This paper confirmed that TB patients in this study possessed high TB knowledge especially among male and married patients with low household income. Also, the findings revealed that most TB patients understood that smoking increases the risk of TB infection, yet, they did not quit smoking which explains that majority of them have been diagnosed with TB for more than five years. Despite the patients possessed high TB knowledge, results on their attitude towards family, friends, and neighbours indicated that the patients did not distance themselves from others which might cause infections. In fact, in terms of TB practices; most patients still reluctant to wear facial mask in public.

Novelty - Hence, the strategies to end the TB epidemic in Malaysia by 2035 should be improved so that the quality of life for the ageing population can be assured.

Type of Paper: Empirical.

Keywords: United Nations' Sustainable Development Goals (SDGs); Malaysia; ageing population; infectious disease; tuberculosis (TB); patient; healthcare; policy

Reference to this paper should be made as follows: Mokhtar, K.S; Rahman, N.A; Haron, M.S. (2020). Complying with the United Nations' Sustainable Development Goals: A case of the Malaysian ageing population, Global J. Bus. Soc. Sci. Review 8(1): 01 - 11. https://doi.org/10.35609/gjbssr.2020.8.1(1)
\end{abstract}

JEL Classification: I12, I19

\section{Introduction}

Global challenges to end poverty, reduce inequalities, and protect the planet necessitate global sustainability (Gupta \& Vegelin, 2016; Zdjelar, Hrustek, \& Sampor, 2019).

\footnotetext{
* Paper Info: Revised: January 13, 2020

Accepted: March 31, 2020

* Corresponding author: Khairiah Salwa Mokhtar

E-mail: khairiah@usm.my

Affiliation: Political Science Department, School of Distance Education, Universiti Sains Malaysia, Malaysia
} 
The responsive efforts to curb these challenges manifested with the adoption of the United Nations' 2030 Agenda for Sustainable Development (Sustainable Development Goals, 2015; Matei, Saghin, Dumitrache, \& Nae, 2018). Established in 2015, this agenda featured 17 goals for all individuals of all ages within a society and is known as the Sustainable Development Goals (SDGs). Among the goals, two goals, namely, Good Health and Wellbeing (Goal 3) and Reduced Inequalities (Goal 10), are closely related to patients within the ageing population.

However, based on a report by the United Nations, the progression to achieve the SDGs has been slower than the initial plan, and most vulnerable people and some countries continue to suffer. For Goal 3, tuberculosis remains a major disease due to late detection and treatment (UN, 2019). In addition, half of the global population lacks access to basic healthcare services. Together with the 21 st century's largest challenge to all countries, the increase in the ageing population, concerted efforts are required to properly meet the SDGs. Governmental actions to respond and adapt to the demographic changes are crucial to ensure costeffective health interventions, especially when dealing with patients from low socioeconomic groups. In Malaysia, these patients are referred to as the B40 group, which refers to patients whose household monthly income is in the bottom 40\%, or below RM 3,900 (USD 930).

Among the significance of this study are as follow. This study offers significant evidence-based analysis of emotional and social outlooks on ageing populations, especially among those who are infected with TB. To the researcher's knowledge, patients' perspectives on preventing Tuberculosis or TB infection with respect to SDG progress has not been explored yet in Malaysia. In fact, a comprehensive study to understand TB from the patients' points of view is still lacking. Thus, it is difficult for health professionals to find an effective way to educate TB patients. As patients age, they require more specific needs, and these requirements add to the complexity of formulating a systematic clinical or treatment solution to prevent drugresistant tuberculosis, which remains a threat worldwide.

Due to the complexity of the ageing population and stigma of elderly TB patients, both conditions are marginalised, regarded as sensitive, and thus demand broader but cautious government attention.

In addition to struggling to achieve the global initiatives of the SDGs, Malaysia's aspirations to end the TB epidemic by the year 2035 and preserve the rights of the emerging ageing population are equally important. In these circumstances, government efforts must be thorough and tailored to each group to ensure smooth compliance with SDGs. This study assumed senior citizens' level of health awareness and preventive measures for TB differ from those of younger age cohorts (Huddart, Bossuroy, Pons, Baral, Pai, \& Delavallade, 2018). Thus, we unearthed to what extent ageing TB patients' knowledge affects their attitude and preventive practices. Thereafter, it could be justified whether or not the Malaysian government has successfully managed the ageing population and TB in compliance with SDGs.

This paper is structured as follows. The next section is dedicated for literature review on the issue of ageing population as a global threat of demographic changes and how medical perspectives viewed the risk of ageing population and infectious disease. It is followed by a brief overview of Health Belief Model, the underlying theory that guides this study. The subsequent section outlines the research methodology and reports the results of this study. The final section presents the discussion and ends with the concluding remarks as well as the suggestions for future research.

\section{Literature Review}

A global partnership to concentrate on sustainable development has consistently stressed the important roles of government and stakeholders to respond and commit extensive efforts to achieve the SDGs (Tamsma \& Costongs, 2018; Zdjelar et al., 2019). Within the context of ageing population and TB disease, both phenomena still prevalent and posed a serious threat to the global community. Despite the severity of TB infection and the extent it involved ageing population, these topics are deemed as under-researched and less attention had been invested to acknowledge these challenging issues effectively (Negin, Abimbola, \& Marais, 
2015). In fact, lack of research and insufficient data to capture the impact of TB among ageing patients hampered the SDGs performance. In other words, the efforts to meet SDGs are equally at risk. Working with limited past studies on ageing population and TB disease, the literature review was summarized as follows.

Previously, researchers argued that the world is facing a greater challenge than economic crises, climate change, and extreme poverty, which emphasises the rapid demographic change and growing proportion of the ageing population (Kwan \& Drolet, 2015). Indeed, Kwan and Drolet (2015) affirmed that the success of achieving the SDGs depends on the ability to manage the global ageing phenomenon. In addition, Tamsma and Costongs (2018) discussed social inequalities and health promotion in the context of the SDGs. The authors revealed that engagement between health professionals and the at-risk population affects the ageing patient's life course. In particular, providing information on healthcare and age-related concerns, raising public awareness of infectious disease, and empowering patients with appropriate knowledge are capable of equipping patients to anticipate and respond to disease, which leads to better preventive measures and health outcomes.

Rajagopalan (2001) argued that clinical symptom of TB in older people may be confused with age-related illness. On top of that, the therapy sessions prepared for ageing patients are challenging since there are higher possibility of adverse drug reactions. Therefore, the author suggested that developing and least developed countries to learn from developed country on how to contain infectious diseases particularly TB contagion. Among the successful measures are implementing efficient DOT or also known as Directly Observed Therapy (DOT), develop more stringent infection control practices, and continuously evaluate TB management efforts as means of prevention and control strategies among high risk population specifically the ageing TB patients. In another study, Negin et al. (2015) stressed that necessary pressure need to be driven by the authority to ensure that proper medication, early detection programme, and health resources should be adequately supplied to cater the specialised needs of ageing population. Indeed, the authors are in agreement with previous studies (Rajagopalan, 2001; Shetty, 2012; Kwan \& Drolet, 2015) which mentioned that developed countries are more efficient in controlling TB pandemic because they put emphasis and special attention to the ageing population in terms of health risk and financial constraints. If these two criteria are adequately met, the existing burden of TB contagion can be contained.

From a medical perspective, older people have an increased risk of vulnerability to infectious diseases predominantly related to the respiratory tract and suffer greater morbidity and a higher risk of mortality (Byng-Maddick \& Noursadeghi, 2016; Zhang et al., 2019). In fact, TB notification rates are progressively evident among older people, especially amongst those aged 65 years and older (Negin et al., 2015; Ghweil, Alsenbsy, Badawy, Abdelkarem, \& Helal, 2018; Ku \& Dodd, 2019). The increasing burden of TB among ageing populations is mainly driven by age-related health changes (i.e., deterioration of the immune system and physical constraints). These situations possibly increase adverse drug reactions and limit accessible treatments, which thus dampens the likelihood of TB recovery (Awang, Mansor, Peng, \& Osman, 2017). Empirical studies focusing on the ageing population combined with social and emotional insights from patients with infectious disease marked the national commitment to implement age-inclusive SDGs and reduce inequalities in Malaysia. Considering the complexity of ageing and patient vulnerability, this study complements previous studies on SDGs to incorporate a participatory approach and aimed to assess ageing TB patients' levels of knowledge and to what extent their knowledge influences their attitude and preventive practices.

Most often, the Health Belief Model (HBM) was adopted as the underlying theory to guide the public health research (Abraham \& Sheeran, 2005). Similarly, this present paper echoed the application of HBM to explain and predict the health-related behaviours especially in terms of attitude and practices. Since this study is interested to focus on the KAP model which represents knowledge, attitude, and practices; therefore, HBM is the most suitable theory to represent patients' belief about health issues, capture the health behaviour patterns and proved to be significant in designing behavioural change interventions (Yoshitake, Omori, Sugawara, Akishinonomiya, \& Shimada, 2019). HBM was developed since 1950s to enhance the 
effectiveness of health education and promotion. Recognizing the importance of demographic background of patients such as gender, age, and socio-economic status, the information which known to be linked towards influencing the preventive health-related behaviour (Yoshitake et al., 2019); all background of TB patients were assessed before they were selected as respondents. Therefore, it is imperative to utilise HBM as the primary theory to guide this study in understanding how well the Malaysian government managed the ageing TB patients in compliance with SDGs. In particular, TB patients' demographic data were gathered from the authority to identify the health behaviour patterns namely; health-risk (smoking) and preventive practices. From there, the effort to contain TB disease in Malaysia among ageing TB patients can be analysed.

\section{Research Methodology}

This research was conducted among ageing TB patients from May 2014 to March 2015. The data of TB patients were extracted from the database of the Division of Disease Control at the Ministry of Health of Malaysia (MOH) in selected states of Malaysia with high occurrence of TB cases namely; Selangor, Kuala Lumpur, Penang, Kelantan, Johor, Sabah, and Sarawak. Monotone responses and excessive missing values were discarded, which resulted in 1,368 usable questionnaires from 1,600 registered TB patients with $\mathrm{MOH}$ and yielded an $85.5 \%$ response rate. Patients who had been diagnosed with and/or confirmed to have TB symptoms were selected as respondents based on certain conditions. The inclusion criteria were TB patients aged 60 years and older (ageing TB patients), diagnosed with TB and undergoing TB treatment in government hospitals or health clinics within the $\mathrm{MOH}$. The patients were approached during their follow-up visits, and after granting permission, they were selected for the sample. At this stage, 429 patients were identified as ageing TB patients and a written consent form was signed by each participant and later, collected by the researchers prior to the data collection process. Participation was strictly voluntary, and the patients could withdraw from the study at any time. This study was reviewed and approved by the Medical Research and Ethics Committee (NMRR-11-658-9825) under the MOH..

Missing values were treated with expectation-maximisation (EM), and missing values higher than $20 \%$ were excluded from further analysis due to their potential to bias the results (Roni, 2014). The reliability of the scale was assessed using internal consistency validation based on Cronbach's alpha coefficient $(\alpha)$. The coefficient was 0.911 for the total scale and ranged between 0.763 and 0.953 for each factor. Since the data were obtained from a single source response for independent (TB knowledge and TB attitude) and dependent (TB preventive practices) variables, Harman's single factor test was conducted to assess the common method bias (CMB). The results showed $20.01 \%$ variance for the single factor, which explained less than $50 \%$ of the total variance (Podsakoff, MacKenzie, Lee, \& Podsakoff, 2003; Roni, 2014). Therefore, CMB was not a concern in this study. The questionnaire for ageing TB patients was adapted based on a study by Ul Haq, Hassali, Shafie, Saleem, Farooqui and Aljadhey (2012).

In order to develop a better representation of the sample, the questionnaires were modified to fit a Malaysian ageing population. Even though this study adopted the Health Belief Model (HBM), some variables were combined (as illustrated with dotted lines in Figure 1) and changed to TB Attitude (i.e.: TB Attitude towards family members, friends, and neighbours) due to the elderly limited cognitive function and speech limitations (Schilling \& Gerhardus, 2017). The final version of the questionnaire had 30 items with three domains: Section A: TB knowledge, Section B: TB attitude, and Section C: TB practices. These three sections mirrored the use of Knowledge, Attitude, and Practices (KAP) model which are being applied in most public health research. 


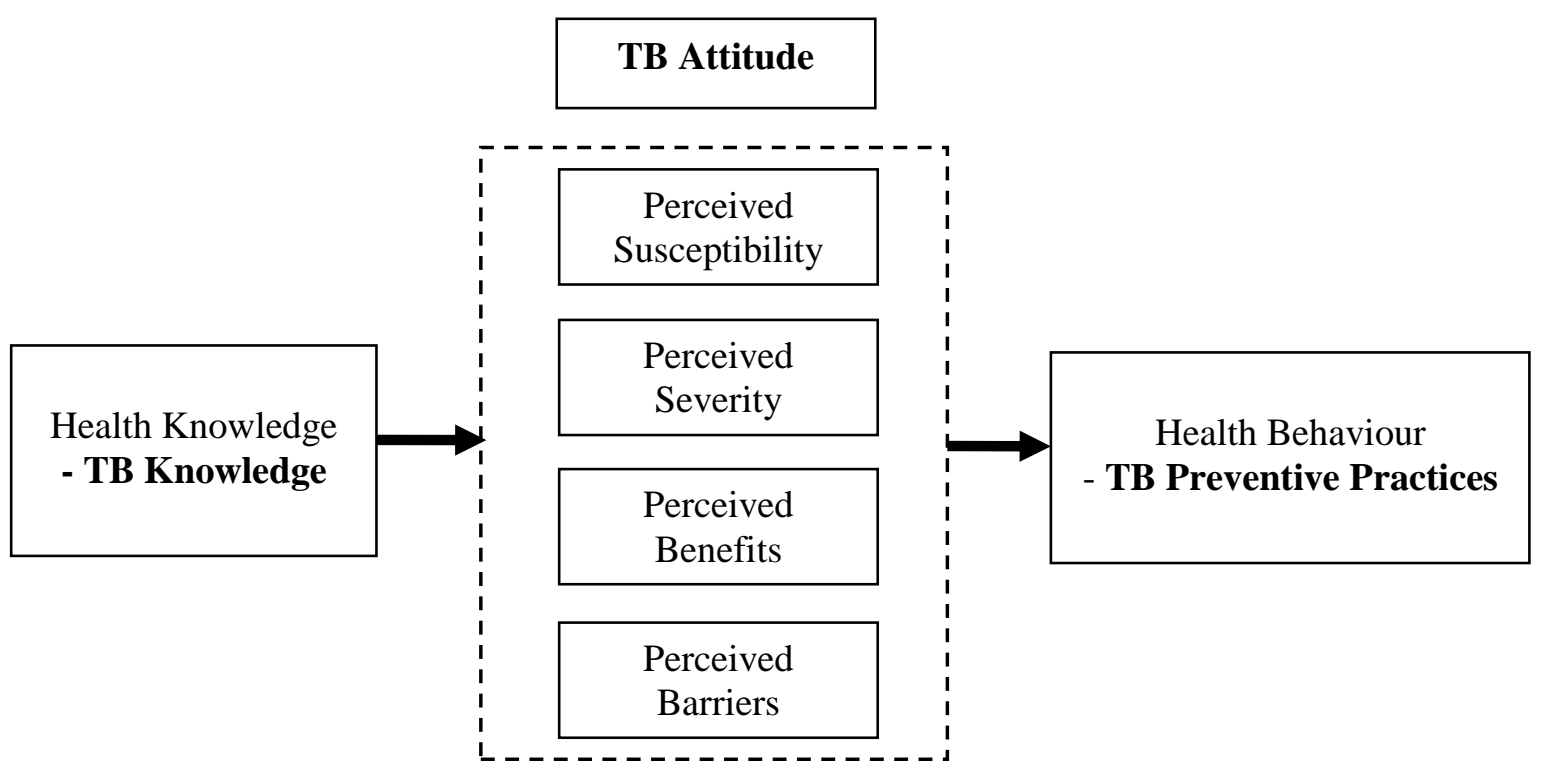

Figure 1: Statistical model: Health Belief Model

\section{Statistics and Results}

Data were entered, cleaned, and analysed using IBM Statistical Package for the Social Sciences (SPSS) version 24. Categorical variables were summarized and presented in a frequency table, and the KolmogorovSmirnov normality results showed that data were not normally distributed $(\mathrm{p}<0.05)$. Thus, a Chi-Square test ( $\chi^{2}$ - test of independence) was employed to compare the difference between subgroups. A p-value of less than 0.05 was statistically significant (Moore, Notz \& Flinger, 2013; Ghweil et al., 2018). Factor analysis was performed using the principal component analysis method to evaluate construct validity. The results showed that the variables were distinct from each other and all items measured the variables accordingly. The loading values ranged from 0.514 to 0.886 . According to Igbaria, Iivari, and Maragahh (1995), loading values greater than 0.50 are considered good and reflect the variable accurately. To justify the appropriateness of factor analysis, the results of the Kaiser-Meyer-Olkin (KMO) test should exceed 0.60, and Bartlett's test of sphericity should be significant (Roni, 2014). The KMO value was sufficient at 0.879 , and the Bartlett's result was significant (Ramayah, 2011).

Most respondents were male $(n=272,63.4 \%)$ and married $(n=339,79 \%)$, and their highest level of education was primary school $(n=160,37.3 \%)$. Most elderly TB patients in this study were considered to belong to the B40 group ( $\mathrm{n}=387,90.2 \%)$. In general, this study reflects the actual global data of ageing TB patients, which are also mostly male and married patients who have low household incomes (Mokhtar \& Rahman, 2017; Perriot, Underner, \& Peiffer, 2018). Even though some of the questions were left unanswered, the percentage of questions without an answer was less than $10 \%$ and, thus, did not influence the overall data.

Since previous studies have shown smoking is associated with an increased risk of TB (Boeckmann et al., 2018; Perriot et al., 2018; Zhang et al., 2019), six questions were asked about patients' smoking behaviour. In general, most of the respondents were not smokers $(n=300,69.9 \%)$ but admitted that they quit smoking after being diagnosed with or infected by TB. Patients who were smokers disclosed that they had been smoking for more than 20 years $(n=75,17.5 \%)$, between 11 and 20 years $(n=34,7.9 \%)$, or less than 10 years $(n=16$, $3.8 \%)$, and three of them did not answer. More than half of the respondents $(n=241,56.2 \%)$ agreed that smoking increases the risk of TB infection, while some confessed they did not know ( $\mathrm{n}=160,37.3 \%$ ). According to Bai, Lee, Chien, Suk, and Chiang (2016), TB patients who smoke cigarettes possessed nearly 
twice the risk of TB infection of non-smokers. In fact, smokers (with TB disease) have a nine times greater risk of mortality than non-smokers (Hutahaean, 2013; Zhang et al., 2019).

In terms of TB knowledge, ten questions were asked, as in Table 1. Five questions were related to TB awareness and TB medical history. The other five questions were related to basic knowledge on TB (Ul Haq et al., 2012). Each correct answer was allotted a score of one, and the level of TB knowledge was divided into three categories: low (1-2), moderate (3), and high (4-5). TB spreads through coughing, sneezing, talking, and spitting and is caused by the Mycobacterium tuberculosis bacterium. Overall, respondents showed a high level of TB knowledge $(n=375,87.4 \%)$.

Table 1. TB Knowledge

\begin{tabular}{|c|c|c|c|c|}
\hline & TB knowledge & $\begin{array}{c}\text { Yes } \\
\text { n }(\%)\end{array}$ & $\begin{array}{c}\text { No } \\
\text { n }(\%)\end{array}$ & $\begin{array}{c}\text { Not sure } \\
\text { n }(\%)\end{array}$ \\
\hline 1. & $\begin{array}{c}\text { Before being infected with TB, did you know about } \\
\text { TB? }\end{array}$ & $297(69.2)$ & $132(30.8)$ & - \\
\hline 2. & Do you what TB is? & $294(68.5)$ & $133(31.0)$ & $2(0.50)$ \\
\hline \multirow[t]{4}{*}{3.} & How long have you been a TB patient? & & & \\
\hline & - Less than five years & $21(4.90)$ & - & - \\
\hline & - Five to ten years & $369(86.0)$ & - & - \\
\hline & - More than ten years & $2(0.50)$ & - & - \\
\hline 4. & Do you know any TB patients? & $77(17.9)$ & $338(78.8)$ & $14(3.30)$ \\
\hline \multirow[t]{5}{*}{5.} & How does TB spread? & & & \\
\hline & - Coughing & $408(95.1)$ & $20(4.70)$ & $1(0.20)$ \\
\hline & - Sneezing & $328(76.5)$ & $91(21.2)$ & $10(2.30)$ \\
\hline & - Talking & $254(59.2)$ & $162(37.8)$ & $13(3.00)$ \\
\hline & - Spitting & $239(55.7)$ & $179(41.7)$ & $11(2.60)$ \\
\hline \multirow[t]{5}{*}{6.} & What causes TB? & & & \\
\hline & - Germ/bacteria & $352(82.1)$ & $71(16.6)$ & $6(1.40)$ \\
\hline & - Virus & $230(53.6)$ & $180(42.0)$ & $19(4.40)$ \\
\hline & - Genetics & $119(27.7)$ & $300(69.9)$ & $10(2.30)$ \\
\hline & - Contaminated food/beverages/water & $104(24.2)$ & $312(72.7)$ & $13(3.00)$ \\
\hline 7. & Is TB infectious? & $388(90.4)$ & $5(1.20)$ & $36(8.40)$ \\
\hline 8. & Can TB be avoided? & $339(79.0)$ & $9(2.10)$ & $81(18.9)$ \\
\hline 9. & Can TB be treated? & $390(90.9)$ & $2(0.50)$ & $37(8.60)$ \\
\hline \multirow[t]{5}{*}{10.} & How long is TB treatment? & & & \\
\hline & - Six months & $286(66.7)$ & - & - \\
\hline & - One year & $38(8.90)$ & - & - \\
\hline & - No answer & 77 (17.9) & - & - \\
\hline & - Wrong answers (One month, three months) & $28(6.50)$ & - & - \\
\hline
\end{tabular}

The analysis of TB attitude was divided into three categories: attitudes towards family members, friends, and neighbours. There were ten questions to measure attitude, as presented in Table 2. The majority of patients were open about their condition and did not mind eating, drinking, and communicating with their family, friends, and neighbours. However, the percentage of patients who trusted others significantly decreased from family to friends and was even lower for neighbours. Patients tended to be more honest with their family than with their friends and neighbours. Unexpectedly, TB patients felt more ashamed of their TB with their friends than their neighbours. 
Table 2. TB Attitude

\begin{tabular}{|c|c|c|c|c|}
\hline & TB attitude & $\begin{array}{c}\text { Family } \\
\text { Yes } \\
\text { n }(\%)\end{array}$ & $\begin{array}{c}\text { Friends } \\
\text { Yes } \\
\mathrm{n}(\%)\end{array}$ & $\begin{array}{c}\text { Neighbours } \\
\text { Yes } \\
\text { n }(\%) \\
\end{array}$ \\
\hline 1. & $\begin{array}{c}\text { Do not mind eating } \\
\text { together }\end{array}$ & $\begin{array}{c}339 \\
(79.0)\end{array}$ & $\begin{array}{c}297 \\
(69.2)\end{array}$ & $285(66.4)$ \\
\hline 2. & $\begin{array}{l}\text { Do not mind drinking } \\
\text { together }\end{array}$ & $\begin{array}{c}340 \\
(79.3)\end{array}$ & $\begin{array}{c}296 \\
(69.0)\end{array}$ & $285(66.4)$ \\
\hline 3. & $\begin{array}{l}\text { Do not mind } \\
\text { communicating together }\end{array}$ & $\begin{array}{c}336 \\
(78.3)\end{array}$ & $\begin{array}{c}290 \\
(67.6)\end{array}$ & $291(67.8)$ \\
\hline 4. & $\begin{array}{c}\text { Do not feel ashamed of } \\
\text { TB infection }\end{array}$ & $\begin{array}{c}339 \\
(79.0)\end{array}$ & $\begin{array}{c}233 \\
(54.3)\end{array}$ & $289(67.4)$ \\
\hline 5. & $\begin{array}{c}\text { Will not stay away from } \\
\text { them }\end{array}$ & $\begin{array}{c}350 \\
(81.6)\end{array}$ & $\begin{array}{c}291 \\
(67.8)\end{array}$ & $291(67.8)$ \\
\hline 6. & $\begin{array}{l}\text { Do not mind if they visit } \\
\text { me }\end{array}$ & $\begin{array}{c}334 \\
(77.9)\end{array}$ & $\begin{array}{c}299 \\
(69.7)\end{array}$ & $296(69.0)$ \\
\hline 7. & $\begin{array}{l}\text { Feel comfortable when } \\
\text { they are around }\end{array}$ & $\begin{array}{l}329 \\
(76.7)\end{array}$ & $\begin{array}{c}296 \\
(69.0)\end{array}$ & $283(66.0)$ \\
\hline 8. & $\begin{array}{l}\text { Feel comfortable living } \\
\text { in the same house }\end{array}$ & $\begin{array}{c}334 \\
(77.9)\end{array}$ & N/A & N/A \\
\hline 9. & $\begin{array}{l}\text { Feel comfortable being } \\
\text { taken care of by them }\end{array}$ & $\begin{array}{c}338 \\
(78.8)\end{array}$ & N/A & N/A \\
\hline 10. & $\begin{array}{l}\text { Not concealing my TB } \\
\text { from them }\end{array}$ & $\begin{array}{c}368 \\
(85.8) \\
\end{array}$ & $\begin{array}{c}291 \\
(67.8) \\
\end{array}$ & $286(66.7)$ \\
\hline
\end{tabular}

Out of the 15 questions to assess good TB preventive practices (see Table 3), 8 questions had a substantially higher percentage than other practices: maintaining cleanliness of external and internal areas of the house, being concerned about their family members and friends who had a fever or were unwell and needed to see the doctor immediately, and caring about personal hygiene, especially in public areas.

Table 3. TB Practices

\begin{tabular}{|c|c|c|c|c|}
\hline & TB practices & $\begin{array}{c}\text { Yes } \\
\text { n }(\%)\end{array}$ & $\begin{array}{c}\text { No } \\
\text { n }(\%)\end{array}$ & $\begin{array}{c}\text { No answer } \\
\text { n }(\%)\end{array}$ \\
\hline 1. & Maintain the cleanliness of my house (external area) & $417(97.2)$ & $4(0.90)$ & $8(1.80)$ \\
\hline 2. & Maintain the cleanliness of my house (internal area) & $414(96.5)$ & $2(0.50)$ & $13(3.00)$ \\
\hline 3. & Take care of personal hygiene in a public area & $378(88.1)$ & $13(3.00)$ & $38(8.80)$ \\
\hline 4. & Wear a mask in public & $270(62.9)$ & $82(19.1)$ & $77(17.9)$ \\
\hline 5. & Cover my mouth when I cough/sneeze & $344(80.2)$ & $21(4.90)$ & $64(14.9)$ \\
\hline 6. & Throw tissues in the dustbin after I cough/sneeze & $358(83.4)$ & $21(4.90)$ & $50(11.6)$ \\
\hline 7. & Wash my hands after I cough/sneeze & $347(80.9)$ & $20(4.70)$ & $62(14.4)$ \\
\hline 8. & Do not share food containers with others & $329(76.7)$ & $26(6.10)$ & $74(17.2)$ \\
\hline 9. & Wash hands before eating & $378(88.1)$ & $8(1.90)$ & $43(10.0)$ \\
\hline 10. & Immediately seek treatment if unwell & $383(89.3)$ & $7(1.60)$ & $39(9.10)$ \\
\hline 11. & Advise family members to see the doctor if they are unwell & $395(92.1)$ & $6(1.40)$ & $28(6.50)$ \\
\hline 12. & Bring family members to see the doctor if they are unwell & $387(90.2)$ & $6(1.40)$ & $36(8.40)$ \\
\hline 13. & Advise friends to see the doctor if they are unwell & $385(89.7)$ & $7(1.60)$ & $37(8.60)$ \\
\hline 14. & Bring friends to see the doctor if they are unwell & $364(84.8)$ & $14(3.30)$ & $51(11.9)$ \\
\hline 15. & Avoid crowded places & $370(86.2)$ & $15(3.50)$ & $44(10.3)$ \\
\hline
\end{tabular}


The Chi-Square test for independence was employed to explore the relationship between two categorical variables, each with two or more categories (Pallant, 2013). Since the p-values were greater than the significance level ( $p>0.05)$, it can be concluded that there is insufficient evidence to suggest an association between gender $[\chi 2(1)=1.327, p=0.249]$, marital status $[\chi 2(2)=2.682, p=0.262]$, and occupation $\left[\chi^{2}(4)=7.337\right.$, $\mathrm{p}=0.119]$ with the level of TB knowledge. However, location showed statistically significant results that the level of TB knowledge varied across different locations $[\chi 2(2)=11.796, p=0.003]$. Patients from urban areas were documented to have a high level of knowledge $(n=158)$, followed by patients from rural areas $(n=110)$ and suburban areas $(n=35)$.

\section{Discussion}

The objectives of this study were achieved: (1) the level of TB knowledge and its influence on patient attitude and preventive practices was identified, and (2) the Malaysian government showed progress in complying with the SDGs (through successfully coping with the ageing population and TB disease). The demographic profile of TB patients is changing worldwide with more patients aged 60 years and older being infected with TB, and Malaysia is no exception to this phenomenon. This study's findings revealed that ageing TB patients in Malaysia demonstrated a high level of TB knowledge, and this knowledge affected their positive attitude and preventive practices to avoid TB transmission to others.

In relation to the second objective, numerous government programmes and health campaigns evidently helped educate and create awareness among Malaysians. In fact, the role of health professionals when dealing with ageing TB patients is of utmost importance. Their patience and ability to explain medical conditions and preventive care in layman's terms to patients, especially to ageing patients, resulted in a higher level of knowledge and better attitude when dealing with TB. In this scenario, government efforts to deal with these two vulnerable groups act as an indication of Malaysia's commitment to end the TB epidemic and passionately work to achieve the SDGs.

Significant differences were found with respect to the level of TB knowledge according to location, and ageing patients who resided in urban areas possessed higher TB knowledge than those who lived in rural or suburban areas. These differences could be attributed to the patients' personal life encounters through past experiences, social contact, and media exposure (Huddart et al., 2018). In other words, knowledge on TB not only was derived from the health institutions but also resulted from family awareness and the influence of spouses and extended family members (in-laws, relatives, etc.). Correct information on TB and a high level of TB knowledge represented a source of empowerment for patients to minimize the risk of transmission (Kigozi, Heunis, Engelbrecht, van Rensburg, \& van Rensburg, 2017).

Efforts to improve TB preventive practices have emerged as an ongoing discussion among health professionals, and recently, it has been a topical issue for gerontology researchers and policy makers. Gerontology is the scientific study of phenomena related to ageing and problems associated with the ageing population. A wide array of studies on ageing and TB disease established a common view that the risk of TB infection increases with age (Byng-Maddick \& Noursadeghi, 2016; Ku \& Dodd, 2019). Indeed, more problems related to the ageing population were discovered, and it is becoming a public health concern worldwide. According to Zhang et al. (2019), a high level of TB knowledge, especially among ageing patients, is important to reduce the incidence of TB infection. With the proper knowledge on TB, patients will be motivated to seek treatment, complete the treatment as scheduled, and eventually be cured of TB. It is imperative for patients to know that they can be cured so that their self-determination for survival is high.

Ageing TB patients have created new demands for healthcare systems and necessitated more stringent policy changes, especially those related to public health. Until recently, ageing TB patients have been largely overlooked; thus, clinical care and specialized treatment to fit their limited physical constraints, immune system function, and drug tolerance are unable to control the TB epidemic (Smit et al., 2015; Ku \& Dodd, 2019). Working on recommendations from past studies, the inclusion of ageing lifestyle factors, such as smoking and social relationships among friends and neighbours, are among the best ways to justify the TB

Global J. Bus. Soc. Sci. Review 8 (1) $01-11$ (2020) 
risk and predict TB transmission to others (Smit et al., 2015; Matei et al., 2018). With advancing age, patients in this study confirmed that social relationships begin to fade away, and patients were reported to choose family members over friends and neighbours. After being diagnosed with TB, ageing patients felt isolated and preferred to stay indoors rather than go out and socialise. Therefore, more social programmes are recommended to include ageing $\mathrm{TB}$ patients, engage them with the community, and provide extended emotional support to patients.

\section{Conclusion}

Given the rapidly growing phenomena of global ageing population and prevalence of TB disease in the ageing population, it would be prudent to embark on more detailed observation for this age cohort. Comparable to other empirical studies, this study has limitations. First, the use of a cross-sectional research design limits the ability to capture the changes in patients' levels of knowledge, attitudes, and preventive practices over time. It is recommended that a longitudinal approach be performed to provide more comprehensive perspectives of ageing TB patients. In addition, a larger sample size and the use of secondgeneration analysis, such as bootstrapping using SmartPLS, are required for better statistical analysis. In addition, the enforcement of public health intervention can be improved by initiating a compulsory programme among ageing patients to educate them on TB knowledge and how to exercise necessary preventive practices to prevent TB transmission to others. Indeed, future research is directed to expand the questionnaire and identify whether the scale is applicable to other countries and different cultures. From a practical perspective, the findings of this study also have implications for health professionals and policy research. First, it is recommended for the government to collaborate with health professionals to develop specific health campaigns for ageing populations. To align with the SDGs' pledge to leave no one behind, this vulnerable group must be empowered. Responding to ageing populations and patients' needs and constraints contributes to meeting the SDGs. Hence, the goals to end the TB epidemic in Malaysia by 2035 can be realized, and the quality of life within the ageing population can be assured.

\section{Acknowledgements}

The research is being funded by the Ministry of Education, Malaysia's Long-Term Research Grant Scheme (LRGS - 203.PJJAUH.67212003) and Universiti Sains Malaysia 2019 Fellowship Scheme.

\section{References}

Abraham, C., \& Sheeran, P. (2005). The health belief model. Predicting Health Behaviour, 2, 28-80

Awang, H., Mansor, N., Nai Peng, T., \& Nik Osman, N. A. (2018). Understanding ageing: fear of chronic diseases later in life. Journal of International Medical Research, 46(1), 175-184. https://doi.org/10.1177/0300060517710857

Bai, K. J., Lee, J. J., Chien, S. T., Suk, C. W., \& Chiang, C. Y. (2016). The influence of smoking on pulmonary tuberculosis in diabetic and non-diabetic patients. PloS One, 11(6), e0156677. https://doi.org/10.1371/journal.pone.0156677

Boeckmann, M., Nohavova, I., Dogar, O., Kralikova, E., Pankova, A., Zvolska, K., \& Sheikh, A. (2018). Protocol for the mixed-methods process and context evaluation of the TB \& Tobacco randomised controlled trial in Bangladesh and Pakistan: A hybrid effectiveness-implementation study. BMJ Open, 8(3), 1-10. https://doi.org 10.1136/bmjopen-2017019878

Byng-Maddick, R., \& Noursadeghi, M. (2016). Does tuberculosis threaten our ageing populations? BMC Infectious Diseases, 16(1), 1-5. https://doi.org/10.1186/s12879-016-1451-0

Ghweil, A. A., Alsenbsy, M. A. R., Badawy, M., Abdelkarem, M. M., \& Helal, M. M. (2018). Pattern of Tuberculosis in Elderly Patients in Egypt. Journal of Tropical Diseases, 6(2), 1-9. https://doi.org/10.4172/2329-891X.1000262

Gupta, J., \& Vegelin, C. (2016). Sustainable development goals and inclusive development. International Environmental Agreements: Politics, Law and Economics, 16(3), 433-448. https://doi.org/10.1007/s10784-016-9323-z. 
Huddart, S., Bossuroy, T., Pons, V., Baral, S., Pai, M., \& Delavallade, C. (2018). Knowledge about tuberculosis and infection prevention behavior: A nine city longitudinal study from India. PloS One, 13(10), 1-15. https://doi.org/10.1371/journal.pone.0206245

Hutahaean, L. M. (2013). Effects of Smoking Habit on the Development of Tuberculosis Disease. IOSR Journal of Nursing and Health Science, 2(5), 24-29.

Igbaria, M., Iivari, J., \& Maragahh, H. (1995). Why do individuals use computer technology? A Finnish case study. Information \& Management, 29(5), 227-238. https://doi.org/10.1016/0378-7206(95)00031-0

Kigozi, N. G., Heunis, J. C., Engelbrecht, M. C., van Rensburg, A. P. J., \& van Rensburg, H. D. (2017). Tuberculosis knowledge, attitudes and practices of patients at primary health care facilities in a South African metropolitan: research towards improved health education. BMC Public Health, 17(1), 1-8. https://doi.org/10.1186/s12889-017-4825-3. https://link.springer.com/article/10.1186/s12889-017-4825-3

$\mathrm{Ku}$, C. C., \& Dodd, P. J. (2019). Forecasting the impact of population ageing on tuberculosis incidence. PloS One, 14(9), 1-13. https://doi.org/10.1371/journal.pone.0222937

Kwan, C., \& Drolet, J. (2015). Towards age-inclusive sustainable development goals: exploring the potential role and contributions of community development. Community Development Journal, 50(4), 589-607. https://doi.org/10.1093/cdj/bsv036

Matei, E., Saghin, D., Dumitrache, L., \& Nae, M. (2018). Multidimensional approach on sustainability of ageing in Romanian residential care centres for elders. Sustainability, 10(9), 1-16. https://doi.org/10.3390/su10093336

Mokhtar, K., \& Rahman, N. A. (2017). Social determinants of tuberculosis contagion in Malaysia. Annals of Tropical Medicine and Public Health, 10(5), 1215-1220. https://doi.org/10.4103/ATMPH.ATMPH_371_17

Moore, D. S., Notz, W. I., \& Flinger, M. A. (2013). The basic practice of statistics (6th ed.). New York, NY: W. H. Freeman and Company.

Negin, J., Abimbola, S., \& Marais, B. J. (2015). Tuberculosis among older adults-time to take notice. International Journal of Infectious Diseases, 32, 135-137. https://doi.org/10.1016/j.ijid.2014.11.018

Perriot, J., Underner, M., \& Peiffer, G. (2018). Tuberculosis and tobacco smoking. Journal of Tuberculosis, $2018,1-4$.

Podsakoff, P. M., MacKenzie, S. B., Lee, J. Y., \& Podsakoff, N. P. (2003). Common method biases in behavioral research: a critical review of the literature and recommended remedies. Journal of Applied Psychology, 88(5), 879-903. https://doi.org/10.1037/0021-9010.88.5.879

Rajagopalan, S. (2001). Tuberculosis and aging: a global health problem. Clinical Infectious Diseases, 33(7), 10341039. https://doi.org/10.1086/322671

Ramayah, T. (2011). Notes for Data Analysis Workshop. Retrieved October 14, 2018 from http://ramayah.com/wpcontent/uploads/2011/04/Data-Analysis.pdf

Roni, S. M. (2014). Introduction to SPSS. SOAR Centre Graduate Research School, Edith Cowan University Joondalup, Australia.

Schilling, I., \& Gerhardus, A. (2017). Methods for involving older people in health research - a review of the literature. International Journal of Environmental Research and Public Health, 14(12), 1-20. doi: https://doi.org/10.3390/ijerph14121476

Shetty, P. (2012). Grey matter: ageing in developing countries. The Lancet, 379(9823), 1285-1287. https://doi.org/10.1016/S0140-6736(12)60541-8

Smit, M., Brinkman, K., Geerlings, S., Smit, C., Thyagarajan, K., van Sighem, A., ... \& Hallett, T. B. (2015). Future challenges for clinical care of an ageing population infected with HIV: a modelling study. The Lancet Infectious Diseases, 15(7), 810-818. https://doi.org/10.1016/S1473-3099(15)00056-0

Sustainable Development Goals. (2015). SDGs: Sustainable Development Goals. Retrieved July 20 , 2019 from https://sustainabledevelopment.un.org/sdgs

Tamsma, N., \& Costongs, C. (2018). Promoting health and well-being in the context of the United Nations Sustainable Development Agenda. Scandinavian Journal of Public Health, 46(1), 44-48. https://doi.org/10.1177/1403494817741773 ul Haq, N., Hassali, M. A., Shafie, A. A., Saleem, F., Farooqui, M., \& Aljadhey, H. (2012). A cross sectional assessment of knowledge, attitude and practice towards Hepatitis B among healthy population of Quetta, Pakistan. BMC Public Health, 12(1), 1-8. https://doi.org/10.1186/1471-2458-12-692

UN. (2019). Special edition: progress towards the Sustainable Development Goals. UN Report. Retrieved October 28, 2019 from https://sustainabledevelopment.un.org/content/documents/22700E_2019_XXXX_Report_of_the_SG_on_the_progress_ towards_the_SDGs_Special_Edition.pdf 
Yoshitake, N., Omori, M., Sugawara, M., Akishinonomiya, K., \& Shimada, S. (2019). Do health beliefs, personality traits, and interpersonal concerns predict TB prevention behavior among Japanese adults?. Plos One, 14(2), 1-10. https://doi.org/10.1371/journal.pone.0211728

Zdjelar, R., Hrustek, N. Z., \& Sumpor, M. (2019). Sustaintable development and active ageing in EU countries-bridges and gaps. Economic and Social Development: Book of Proceedings, 275-284

Zhang, C. Y., Zhao, F., Xia, Y. Y., Yu, Y. L., Shen, X., Lu, W., ... \& Liu, F. Y. (2019). Prevalence and risk factors of active pulmonary tuberculosis among elderly people in China: A population based cross-sectional study. Infectious Diseases of Poverty, 8(7), 1-10. https://doi.org/10.1186/s40249-019-0515-y 